\title{
OS OBJETIVOS DO ENSINO DE HISTÓRIA
}

\author{
Luis Fernando Cerri *
}

Resumo: Discute-se a historicidade dos objetivos no ensino da História, bem como o seu significado contemporâneo, marcado pelos avanços e contradições do momento histórico vivido no ensino da disciplina e no sistema educacional como um todo Palavras-chave: historicidade, objetivos, ensino, prática

\section{Os objetivos como objeto}

Não podemos dizer que as pessoas que escreveram a Bíblia tiveram uma tarefa fácil. Entretanto, não tiveram um tipo de dificuldade próprio dos historiadores (e que deveria ser sempre compartilhada pelo conjunto das ciências humanas). Para os hebreus, bastou escrever que Javé, em solene tom de autoridade disse: "- Faça-se a Luz!" , e a Luz, narram-nos, foi feita. Essa facilidade não a temos nós, historiadores, para quem os objetos não surgem por sopro divino, mas enraízam-se firmemente no processo histórico. Neste nosso ofício, a historicidade dos objetos deve ser um tema obrigatório, de maneira que sua intelegibilidade possa contar com essa referência, que possibilita a interpretação e a crítica. Também porque esse tema, a serventia de se ensinar história, tem sido debatido há mais de uma década, toda vez que, em crise ou não, debruçamo-nos sobre o nosso próprio métier (ver, por exemplo, MUNHOZ, s.d. e ARRUDA, 1995)

Isto posto, sinto-me autorizado, ou melhor, obrigado, a iniciar esse artigo com a referência à história do tema em questão: o ensino de história, enfocado a partir dos seus objetivos. Com

- Doutorando em Metodologia do Ensino (História) pela Faculdade de Educação -

Unicamp, e professor de Metodologia e Prática do Ensino de História na Univ. Estadual de Ponta Grossa (PR), membro do Grupo Memória - Pesquisa no ensino da história. Email: Ifcerri@convoy.com.br. 
base nos textos de François FURET (s.d.) - para o caso francês, que costuma ser, queiramos ou não, modelo para o Ocidente - $\mathrm{e}$ Elza NADAI (1993-4) - no caso específico do Brasil - podemos afirmar que, se a história enquanto ciência (ou arte, ou sistematização de saberes, ou como queiram) é milenar, o ensino da mesma como a conhecemos é fruto dos desdobramentos da história no século XIX, principalmente, sendo um componente importante da própria evolução histórica do período contemporâneo.

A história surge, enquanto disciplina escolar, apenas depois das transformações epistemológicas que transformaram os seus objetos em conteúdo ensinável. A Filosofia das Luzes, no século XVIII, estabelecerá, com maior clareza, um recorte específico do real com campo da história, bem como um método de ação sobre esse campo. A Revolução Francesa e o período napoleônico deixarão claro para os estudiosos que a história processo é transformação, é mudança, e a disciplina estabelecerse-á, então, como o estudo metódico da mudança social no tempo. Evidentemente, estamos presos aqui a uma visão francesa do desenvolvimento da disciplina na Europa, já que neste país os estudos sobre a história e seu ensino são mais desenvolvidos e divulgados, o que limita as afirmações do início do parágrafo a essas condições.

Ao lado dos aspectos epistemológicos, a história nesse período é marcada pelas décadas de luta em que as burguesias nacionais procuram consolidar o seu poder. Uma vez no Estado, ao lado da nobreza ou não, esta classe verá claramente que a história é uma arma, e esta arma deverá ser usada para estabelecer a hegemonia burguesa, no sentido de um consenso social em que fica justificado o poder desta classe e seus aliados. A história, principalmente, será a disciplina capaz de estabelecer uma identidade única, a nacional, sobre todas as outras, que homogeneiza cultural e juridicamente os cidadãos, a partir de um passado comum, que, via de regra, é inventado (cf. "A Invenção das Tradições", de HOBSBAWN, 1984, e "Le Mythe Nacional", de CITRON, 1987). Assim, nas palavras de François FURET, a história na escola do século XIX manifesta-se como a 
"genealogia da nação", como instrumento de unificação ideológica dentro do projeto de construção do consenso burguês, cuja visão de escola é a de uma instituição capaz de igualar o estatuto de todos os homens, convertendo-os de súditos a cidadãos.

Esta digressão sobre a origem da disciplina não nos servirá apenas para estabelecer a historicidade do objeto. Serve, também, para que afirmemos que os objetivos da disciplina também são históricos, do que resultaria absurdo discorrermos sobre os mesmos de maneira universal e genérica, descarnada de um contexto sócio-temporal específico. Ainda que em quase todos os programas e currículos o objetivo da disciplina apareça como "formar o cidadão", a verdade é que este "cidadão" também muda com o tempo e o espaço. O que oficialmente se espera de um cidadão soviético é bem diferente do que se espera de um cidadão americano no governo de Nixon; o mesmo se aplica ao cidadão da primeira república brasileira, do Estado Novo, da Ditadura Militar e do período atual. Prepará-lo para a "democracia" é um problema idêntico, já que os regimes socialistas do Leste Europeu eram conhecidos por alguns como "democracias populares" e os Estados Unidos interviram no Vietnã em defesa da "democracia". Um estudo histórico dos objetivos da disciplina precisaria ser também um estudo das palavras enquanto os lugares privilegiados da memória (Nora, 1986).

Já que iniciamos "biblicamente", faço minhas as palavras de Marilena Chauí, num texto em que comentava a impossibilidade de abordar "Deus e sua época". Essa impossibilidade remete-nos aos recortes do objeto. Assim, a validade das minhas afirmações fica circunscrita à especificidade nacional e contemporânea deste tema, já que, como afirmei acima, o contexto é fundamental na caracterização dos objetivos do ensino.

\section{Os papéis da disciplina}

Nas ciências exatas, é clara e relativamente tranqüila a distinção entre a teoria e a prática. Aí, o campo da teoria é facilmente delimitável: na Química, por exemplo, a teoria é 
constituída pelas generalizações e conclusões oriundas da aplicação de um método a várias experiências, com o que fica estabelecida uma lógica geral das transformações da matéria, em seus múltiplos elementos e condições. Mesmo teorias relativamente recentes, como o princípio da indeterminação, não mudam qualitativamente essa condição geral de exatidão, na qual a prática nada pode mais ser que a aplicação para a criação de produtos e resolução de problemas concretos/materiais. Em história, o que é a aplicação da teoria? A pesquisa? O ensino? A prática política? Particularmente na nossa disciplina, a delimitação entre a teoria e a prática não é exata, e muito menos consensual.

Dúvidas como essa têm gerado uma ampla discussão nos meios educacionais brasileiros. Nas últimas duas décadas, principalmente, vem sendo constante a crítica ao distanciamento entre universidade e escola básica e média, bem como entre ensino e pesquisa. Dentro dessa discussão, a pesquisa, além de atividade teórica, pode ser a prática. Daí a questão: o que é a prática em história?

Sem a pretensão de fechar o assunto, com o auxílio de Klaus BERGMANN (1989-90), podemos arriscar a resposta de que a prática em história é o trabalho de traduzi-la (ou melhor, recompô-la), de conduzi-la do círculo restrito dos especialistas até o grande público. Ainda que não seja o único meio, o ensino é uma das principais formas de realizar aquela tradução. Principalmente através dele, forma-se a consciência histórica de uma sociedade, determina-se a identidade comum, constitui-se o povo, sua maneira de encarar a si próprio e aos outros. Portanto, em última instância, a ação das pessoas no processo histórico, prática por excelência, é fortemente influenciada pela prática de ensino de história. Não é pequeno o tamanho do problema ...

Perante essa enorme responsabilidade, é preciso que os professores, ainda no seu processo inicial de formação, sejam integrados na discussão dos papéis da didática da história: empírico, reflexivo e normativo. O papel empírico do estudo da disciplina é a verificação do que ela de fato ensina hoje, ou seja, 
a coleta de dados que permite construir o perfil da sua situação atual. Pela importância do resultado do ensino de história sobre a população, é necessário que nos detenhamos no papel reflexivo que deve ter a discussão sobre a prática de ensino: perante o que é ensinado, o que poderia e deveria ser ensinado? Essa reflexão conduz tanto à crítica da situação quanto às propostas diante das carências verificadas. O resultado desse ver e desse avaliar constitui o papel normativo da prática de ensino, ou seja, o estabelecimento do que, perante o real e o ideal, efetivamente deve ser ensinado para que possamos alcançar a melhor relação possível entre a prática que forma a consciência histórica e os princípios para a ação na história que beneficiem a maioria da sociedade brasileira.

Se concordamos que a história tem entre seus fardos e alegrias a missão de colaborar com a formação da identidade de um grupo, neste momento está claramente posta a necessidade de questionar a identidade nacional, principalmente a que embasa a comemoração dos "500 anos do Brasil". Que no livro, na aula e no show televisivo é uma identidade de uma unidade e de comunidade forjadas (dessa gente que sofre mas que é feliz e faz carnaval), que no chão das ruas é uma identidade de excluídos, mutilados, uma identidade esquartejada e dolorida (SÃO PAULO, 1992), que é preciso reavaliar e remontar em sua crueza. Por baixo da festa, há uma crise de identidade nacional, que, isso sim, é preciso descobrir.

"Pai, diga-me lá para que serve a história", é a pergunta do garotinho ao pai historiador, narrada por Marc BLOCH em "Le Métier de l' Historien", pergunta geradora para este clássico da historiografia. "Criança diz cada uma ...", secundaria o impagável Pedro Bloch (que, até onde sabemos, não deve ter parentesco com Marc). Essas formidáveis e embaraçantes perguntas próprias de quem quer conhecer o mundo e não tem, como nós, os vícios, inércias e temores da formação acadêmica, levam os adultos a repensar seus conhecimentos. Perante a simplicidade e, ao mesmo tempo, profundidade dessa dúvida, Marc Bloch ofereceu sua obra inacabada. Sem a pretensão de imitá-lo, mas com o objetivo de contribuir humildemente com a quilométrica 
resposta que aborreceria o infante, poderíamos afirmar que a história, quando ensinada, serve para os homens possam pensar historicamente, adicionando à sua reflexão os elementos que não estão presentes no imediato, mas sim no tempo longo, médio e curto. A história ensinada serve para ajudar a criar identidades, mas serve principalmente para que as pessoas reconheçam-se como sujeitos, como parte também de um coletivo, conheçam suas possibilidades e limitações de ação na história. Desta forma, serve também para questionar identidades inventadas, o que não deixa de ser um momento importante do processo de formação da consciência de classe. Hoje, sob um regime democrático limitado, o ensino de história serve para estimular a participação dos indivíduos nas práticas da cidadania, convencer da importância do voto, da organização popular, dos partidos políticos. Por mais belos que pareçam esses ideais, um ensino de história voltado para o desenvolvimento da autonomia (e aqui percebe o leitor que falo a partir de expectativas pessoais dos objetivos da história, junto com o meu grupo de identificação) não deve ser uma correia de transmissão dos conceitos hegemônicos de cidadania e ação política. Deve, pelo exemplo de outros lugares e outras épocas, colocar o nosso sistema e os nossos valores sob discussão, para que o aluno perceba por si mesmo as limitações e os interesses envolvidos na montagem das estruturas que regem o nosso cotidiano. Repetir o discurso oficial, por mais que se aproxime do que imaginamos como ideal de poder, limita as perspectivas do aluno, e faz do professor de história um inocente útil.

O ensino da história serve, (muito) finalmente, para contribuir para que os educados contribuam para a tão difícil e utópica construção da felicidade humana. Essa é uma resposta que poderíamos dar, dentro das discussões atuais sobre o assunto, e a partir da realidade política, econômica e social que vivenciamos.

\section{Dificuldades e perspectivas para a consecução desses objetivos}

Esta terceira parte deverá ser um antídoto ao clímax em 
que terminamos a parte anterior. Para que a pieguice não nos tome de assalto, e antes que derramemos uma incauta lágrima perante a beleza dos objetivos, façamos uma breve excursão à escoa de $1^{\circ}$ e $2^{\circ}$ graus, verdadeira vacina contra o romantismo. Lá, esperam-nos dificuldades - mas também facilidades - para a consecução dos objetivos comentados acima.

Em termos de facilidades, o professor tem a vantagem de atuar em uma cultura voltada para a memória. Isso devido à constituição judaico-cristã da civilização ocidental, fator que torna a memória e a lembrança elementos essenciais e constitutivos da personalidade de cada um, uma vez que a nossa cultura surge de visões de mundo para as quais o tempo, a memória e a periodização são centrais. Evidentemente, se nossa cultura não tivesse esse traço, a história e seu ensino não existiriam como problemas a serem enfrentados; mas continuemos: isso não anula aquela facilidade. Além das raízes históricas da cultura ocidental, nunca os temas da história estiveram tão ao alcance da infância e da juventude. Basta verificar os filmes e desenhos animados que assistem, os quadrinhos que lêem, os jogos de computador aos quais têm acesso. Uma sociedade de memória funde-se a uma sociedade de mídia, e recoloca o tempo como dimensão importante da compreensão de nós mesmos (cf. KURZ, 1999). Antigüidade, Idade Média, Moderna e Contemporânea (perdão pelo cacoete eurocêntrico e quadripartite) afloram com freqüência, ainda que de forma não-sistemática, fragmentada, estereotipada e mesmo equivocada. Mas já temos um ponto de partida bem melhor que o das gerações de nossos pais e avós, para quem a história estava bem mais distante, confinada principalmente nos livros.

Sobre as dificuldades, podemos afirmar que a natureza central das mesmas não está nas características da disciplina, mas sim nos métodos através dos quais ela chega aos educandos. O ensino tradicional (ligado também a uma concepção tradicional da disciplina), sem acabar, já nos deixa uma herança em dívidas: os alunos têm sido obrigados, ao longo do tempo, a engolir uma história estática, linear e cronológica, sucessão arbitrária e obrigatória de eventos e nomes, com pouco 
ou nenhum sentido para a sua vida ou formação intelectual. Essa situação já fez arraigar um preconceito sobre a disciplina, que, com motivos, coloca-a como "fácil" (afinal depende apenas de uma memorização eficiente) e secundária (pois pouco contribui para a compreensão do mundo, com sua sucessão de impérios, fases da Revolução Francesa, batalhas da Segunda Guerra Mundial, etc.).

Um outro problema sério é a utilização de novos recursos e metodologias (às vezes não por convicção, mas pelo fascínio e pressão que a palavra "novo" exerce) sem a devida fundamentação teórica do professor, e de forma isolada, como planta exótica no pântano de uma estrutura tradicional de ensino. Por vezes, essa má condução de novos métodos apenas cria mais confusão e ojeriza nos alunos, na medida em que não conseguem se adaptar às novas posturas e habilidades exigidas, dissonantes da sua prática escolar anterior. Ressalve-se, entretanto, o sucesso de muitas experiências.

\section{A história ensinada em seus caminhos}

Vivemos num período de mudanças e questionamentos em todos os sentidos da existência humana. Os paradigmas do século $X X$, que até há pouco tiveram validade inquestionada, são discutidos, estão sob dúvida, ou, melhor dizendo, sob julgamento. Econômica, social e politicamente, o mundo caminha para novas formas de organização (e desorganização). Nesse processo todo, a educação é alvo de acirradas polêmicas, e o ensino de história, em crise, procura seus caminhos e suas saídas. É uma crise de crescimento, mas também de luta pela sobrevivência: qual seria a utilidade de uma prática histórica crítica e interpretativa para um mundo em que apenas uma pequena parcela da população precisará pensar (os "analistas simbólicos"), restando aos demais as tarefas informatizadas, repetitivas, e o consumo massificado.

Nas últimas décadas, os profissionais do ensino de história, na universidade e na escola, dedicam-se a discutir, avaliar e propor alternativas, estabelecendo várias linhas de reflexão: a 
formação dos professores de história, os aspectos cognitivos nos problemas do ensino - aprendizagem, as metodologias possíveis e seus recursos, a questão do livro didático, as novas experiências de ensino.

Essa discussão já tem gerado alguns frutos, naturalmente polêmicos, como as propostas curriculares (para o $1^{\circ} \mathrm{grau}$ de São Paulo, por exemplo), a avaliação institucional dos livros didáticos, a preocupação do Estado e dos professores com as "novas" linguagens (e, por que não dizer, com as "novas" mensagens também).

Portanto, resta-nos concluir que a presente crise, a tensão entre os objetivos e as metodologias de ensino, configura-se como alvissareira e salutar. No seio desse debate e de suas conseqüências na escola, muitos daqueles nossos objetivos já começam a se realizar. Se a "autodestruição inovadora" do capitalismo não quebrar tudo antes disso.

Abstract: The article discusses the historicity of the objectives of History Teaching, and also his contemporary meaning, marked by the advancements and contraditions of the historical moment lived on the teaching of the subject and in the educacional system as a whole

Key-words: historicity, objectives, teaching, practice

\section{Referências bibliográficas}

1. ARRUDA, Gilmar. Para que serve o ensino de história? História e Ensino. Londrina, v. 1, p. 61-68, 1995.

2. BERGMANN, Klaus. A História na Reflexão Didática. Revista Brasileira de História. São Paulo. v. 9, n. 19, p. 29-42. set.89-fev.90.

3. BLOCH, Marc. Introdução à História. Lisboa, Europa-América, s.d.

4. CITRON, Suzanne. Le Mythe Nacional. Paris, Éditions Ouvrières, 1987.

5. FURET, François. A Oficina da História. Lisboa, Gradiva, s.d. 
6. HOBSBAWN, Eric e RANGER, Terence (orgs.). A Invenção das Tradições. Rio de Janeiro, Paz e Terra, 1984.

7. KURZ, Robert. A expropriação do tempo. Folha de São Paulo, 3 jan 1999.

8. MUNHOZ, Sidney. Para que serve a história ensinada nas escolas? In: SILVA, Marcos A. (org.) Repensando a História. São Paulo: Marco Zero, s.d., p. 65-8.

9. NADAI, Elza. O Ensino de História no Brasil: Trajetória e perspectiva. Revista Brasileira de História. São Paulo. v. 13, n. 25-26, p. 143-162, set 92-ago. 93.

10. NORA, Pierre. Les Mots. In: NORA, Pierre. Les Lieux de Mémoire II - La Nation. Paris, Gallimard, 1986, p. 643-58. 11. SÃO PAULO (Município). Pátria amada, esquartejada. São Paulo: Secretaria Municipal de Cultura/ Departamento do Patrimônio Histórico, 1992. 